\title{
Correlations between Motor Ability with Gait Speed and Cognitive Functions in Rehabilitation Users
}

\section{Hiroya Miyabara1*, Seigo Koura1, Moemi Matsuo', Makoto Uchinoura², Yuki Kishikawa1, Yuji Yamaguchi' ${ }^{1}$, Youhei Komatsu ${ }^{1}$, Seijiro Nishimura ${ }^{2}$, Shinichi Shibata ${ }^{2}$, Hajime Shibata ${ }^{2}$}

\author{
${ }^{1}$ Faculty of Rehabilitation, Nishikyusyu University, Kanzaki, Japan \\ ${ }^{2}$ Kurume Rehabilitation Hospital, Kurume, Japan \\ Email: ^miyabarahi@nisikyu-u.ac.jp
}

How to cite this paper: Miyabara, H., Koura, S., Matsuo, M., Uchinoura, M., Kishikawa, Y., Yamaguchi, Y., Komatsu, Y., Nishimura, S., Shibata, S. and Shibata, H. (2022) Correlations between Motor Ability with Gait Speed and Cognitive Functions in Rehabilitation Users. Open Journal of Therapy and Rehabilitation, 10, 1-8.

https://doi.org/10.4236/ojtr.2022.101001

Received: November 25, 2021

Accepted: January 3, 2022

Published: January 6, 2022

Copyright $\odot 2022$ by author(s) and Scientific Research Publishing Inc. This work is licensed under the Creative Commons Attribution International License (CC BY 4.0).

http://creativecommons.org/licenses/by/4.0/ (c) (i) Open Access

\begin{abstract}
Purpose: To compare and examine motor and cognitive functions in people who require support, and in healthy elders. Method: The variables of age, BMI, educational background, blood pressure, grip strength, knee extension, gait speed, MMSE, and subjective health feeling for 36 rehabilitation users and 22 healthy elders were assessed. We compared and examined motor and cognitive functions in rehabilitation users who need support and healthy elders. Results: The percentage of MMSE scores with 27 points or higher and that of subjective health feeling with 3 points or higher were significantly higher in healthy elders than in rehabilitation users. Systolic and diastolic blood pressure were significantly higher in rehabilitation users than in healthy elders. Gait speed and MMSE scores were significantly higher in healthy elders than rehabilitation users. Conclusion: Gait speed could be used for physical fitness in elders. Gait speed was the best physical fitness measurement for elders. Gait speed of rehabilitation users was strongly related to MMSE scores. Gait speed could be a determinant of MMSE scores.
\end{abstract}

\section{Keywords}

Elderly, Gait Speed, Motor Ability, Rehabilitation Users,

The Long-Term Care Insurance

\section{Introduction}

The gait speed test is an easy assessment tool that widely used for the aging researches [1]. Moreover, it can predict a future decrease in activities of daily liv- 
ing (ADL), and also elderly people's motor functions including muscle strength, balance and flexibility are able to represent walking velocity [2]. In addition, it was reported that elderly people's functional capacity was predictable by their gait speed [3]. Furthermore, the decrease in gait speed is a common process in aging and is often associated with several adverse health effects, such as weakness [4], falls [5], hospitalizations [6] and poor quality of life [7]. Gait speed has been directly related to cognitive abilities of an individual [8] [9] and it is considered an indicator of elderly who are at high risk for the cognitive decline [10] [11].

Based on these, it might be possible that gait speed can be a predictive factor of inclusive physical functions. In the present study, we examined relations between gait speed, motor ability and cognitive functions in rehabilitation users who need supports and in healthy elders to clarify the facts. Thus, the objective of present study is to clarify the relationship between gait speed and motor ability, Mini-Mental State Examination (MMSE) for 36 elderly persons who use day-service rehabilitation.

\section{Subject and Methods}

\subsection{Participants}

Thirty-six rehabilitation users ( $81.3 \pm 5.7$ years; 11 males and 26 females) and 22 healthy elders (79.1 \pm 4.6 years; 7 males and 15 females) participated in this study. 59 subjects accepted the invitation of which 58 subjects could be included in the present study. The remaining 1 subjects were excluded owing to missing details about physical activity $(\mathrm{n}=1)$.

The present investigation was approved by Kurume Rehabilitation Hospital Ethical Review Board for Medical Research Involving Human Subjects (ethical number: 21-001). Collected data included the socio-demographic characteristics (e.g., gender, age, educational background), anthropometric measurements (e.g., height, weight). Body mass index (BMI) was calculated by dividing the weight in kilogram by height in meter squared (Table 1 ).

\subsection{Methods}

We measured height and weight as the physique items and hand grip strength, gait speed test as motor ability items. We evaluated hand grip strength by a mechanical dynamometer with a dominant hand. We asked participants to walk on the straight walkway which consists of $11 \mathrm{~m}$ in length on the flat floor once at their preferred velocity. Gait speed was measured over a $5 \mathrm{~m}$ distance which was between $3 \mathrm{~m}$ to $8 \mathrm{~m}$ from the start line.

Cognitive function was assessed using a 30-question of MMSE; each correctly answered question was awarded one point, whereas incorrect or no answers were awarded zero points. The total score ranged from 0 to 30 points.

This work was supported by the Kabutoyama MS Limited company R, Japan (Kurume Rehabilitation Hospital, NO. 21-001). 
Table 1. Demographic characteristics of participants.

\begin{tabular}{|c|c|c|}
\hline Characteristics & $\begin{array}{l}\text { Rehabilitation users } \\
\qquad(\mathrm{n}=36)\end{array}$ & $\begin{array}{l}\text { Healthy elders } \\
\quad(n=22)\end{array}$ \\
\hline \multicolumn{3}{|l|}{ Gender } \\
\hline Male & $11(31)$ & $7(32)$ \\
\hline Female & $25(69)$ & $15(68)$ \\
\hline \multicolumn{3}{|l|}{ Educational background } \\
\hline Junior school & $17(47)$ & $2(10)$ \\
\hline High school & $19(53)$ & $14(63)$ \\
\hline University & - & $6(27)$ \\
\hline \multicolumn{3}{|l|}{ Level of care needed } \\
\hline Needs 1 & $28(78)$ & - \\
\hline Needs 2 & $8(22)$ & - \\
\hline \multicolumn{3}{|l|}{ Types of diseases } \\
\hline Cerebrovascular disorders & $8(22.2)$ & - \\
\hline Bone and joint disorders & $5(13.8)$ & - \\
\hline Heart disorders & $1(2.8)$ & - \\
\hline Hypertension & $17(47.2)$ & $17(47.3)$ \\
\hline Diabetes mellitus & $4(11.1)$ & - \\
\hline Hyperlipidemia & $1(2.8)$ & - \\
\hline
\end{tabular}

Numbers (\%).

\subsection{Statistics}

IBM SPSS Statistics version 26.0 (SPSS Inc., Chicago, IL, USA) was used for statistical analysis. In this study, all continuous variables are presented as the mean \pm standard deviation (SD) and categorical data are presented as numbers (percentages). Pair analyses were carried out using unpaired Student's t-tests. Correlations were analyzed by Pearson's correlation coefficient among continuous variables. After all, multiple regression analysis was performed for gait speed. The level of significance was set as $\mathrm{P}<0.05^{\star}$.

\section{Results}

Table 1 provides an overview of the participants (rehabilitation users; 11 males and 25 females and healthy elders; 7 males and 15 females). The mean age of the sample was 81.3 years. Seventy-eight percentages of rehabilitation users (78\%) were needed support 1 and forty-seven (47\%) were with hypertension. Rehabilitation users had significantly higher systolic blood pressure $(\mathrm{p}<0.05)$ and diastolic blood pressure $(\mathrm{p}<0.05)$ than healthy elders. Healthy elders had significantly faster gait speed $(\mathrm{p}<0.05)$ and better MMSE scores $(\mathrm{p}<0.05)$ than rehabilitation users (Table 2). Gait speed of rehabilitation users showed significant correlation with MMSE scores $(r=0.50, \mathrm{p}<0.01)$ (Table 3$)$. Table 4 shows the 
Table 2. Comparison of variables between rehabilitation users and elder.

\begin{tabular}{cccc}
\hline Variables & $\begin{array}{c}\text { Rehabilitation users } \\
(\mathbf{n}=36)\end{array}$ & $\begin{array}{c}\text { Healthy elders } \\
(\mathbf{n}=\mathbf{2 2})\end{array}$ & $\boldsymbol{P}$-value \\
\hline Age (year) & $81.3 \pm 5.7$ & $79.1 \pm 4.6$ & 0.13 \\
BMI $\left(\mathrm{kg} / \mathrm{m}^{2}\right)$ & $23.9 \pm 3.9$ & $23.6 \pm 2.6$ & 0.75 \\
Education (year) & $10.9 \pm 1.5$ & $10.4 \pm 1.5$ & 0.40 \\
Systolic blood pressure (mm/Hg) & $142.3 \pm 19.3$ & $127.5 \pm 16.6$ & $0.01^{*}$ \\
Diastolic blood pressure (mm/Hg) & $80.6 \pm 8.3$ & $73.3 \pm 10.0$ & $0.01^{*}$ \\
Grip strength (kg) & $23.8 \pm 7.7$ & $27.0 \pm 9.3$ & 0.20 \\
Knee extension strength (kg) & $13.1 \pm 10.6$ & $15.3 \pm 8.2$ & 0.45 \\
Gait speed (m/second) & $1.38 \pm 0.4$ & $2.48 \pm 0.4$ & 0.01 \\
MMSE (score) & $26.3 \pm 3.0$ & $28.8 \pm 1.5$ & 0.01 \\
\hline
\end{tabular}

Notes: Values are means and SDs, BMI = body mass index; MMSE = mini-mental state examinations. ${ }^{\star} \mathrm{P}<0.05$ by unpaired student's t-tests.

Table 3. Correlation coefficient between gait speed and variables.

\begin{tabular}{ccccc}
\hline \multirow{2}{*}{ Variables } & \multicolumn{2}{c}{ Rehabilitation users } & \multicolumn{2}{c}{ Healthy elders } \\
\cline { 2 - 5 } & Gait speed $(\rho)$ & $P$-value & Gait speed $(\rho)$ & $P$-value \\
\hline Age & -0.33 & 0.07 & 0.29 & 0.27 \\
BMI & 0.22 & 0.25 & 0.28 & 0.29 \\
Systolic blood pressure & 0.12 & 0.50 & 0.20 & 0.44 \\
Diastolic blood pressure & 0.20 & 0.28 & 0.35 & 0.18 \\
Grip strength & 0.35 & 0.06 & -0.25 & 0.34 \\
Knee extension strength & 0.35 & 0.62 & 0.11 & 0.67 \\
MMSE & 0.50 & $0.001^{*}$ & 0.08 & 0.77 \\
\hline
\end{tabular}

Notes: Values are means and SDs, BMI = body mass index; MMSE = mini-mental state examinations. ${ }^{\star} \mathrm{P}<0.05$ by person's correlation coefficient.

Table 4. Multiple regression analysis for gait speed.

\begin{tabular}{ccccc}
\hline \multirow{2}{*}{ Variables } & \multicolumn{2}{c}{ Rehabilitation users } & \multicolumn{2}{c}{ Healthy elders } \\
\cline { 2 - 5 } & $\boldsymbol{\beta}$ & $\boldsymbol{P}$-value & $\boldsymbol{\beta}$ & $\boldsymbol{P}$-value \\
\hline Age & -0.33 & 0.07 & 0.29 & 0.27 \\
Grip strength & 0.35 & 0.06 & -0.25 & 0.34 \\
MMSE & 0.50 & $0.001^{*}$ & 0.08 & 0.77 \\
\hline
\end{tabular}

Notes: MMSE $=$ mini-mental state examinations. ${ }^{\star} \mathrm{P}<0.05$ by multiple correlation coefficient. $\beta$ : multiple correlation coefficient adjusted for the degrees of freedom. $\beta=0.50, \mathrm{P}<$ $0.001, \mathrm{R}=0.97, \mathrm{R}^{2}=0.94$ (gait speed of rehabilitation users). $\beta=0.08, \mathrm{P}=0.08, \mathrm{R}=0.39$, $\mathrm{R}^{2}=0.15$ (gait speed of elders). 
results of the multiple regression models. Gait speed of rehabilitation users was strongly related to MMSE scores, and the determinant of gait speed was MMSE scores.

\section{Discussion}

In the present study, we examined motor ability and cognitive functions among rehabilitation users and healthy elders. The previous studies have shown that gait speed was taking part in $44 \%$ smaller in Rehabilitation users compared with elders [12], and the study which compared cognitive performance and gait speed of elders have shown that rehabilitation users with lower mean cognitive scores were also with lower gait speed [8] [9] [10] [11]. Regarding gait speed, the Brazilian study which investigated pre-frailty and factors associated with this condition, identified significant relationship between slowness of gait and low cognitive functions in elders, and suggested that gait speed could be considered as one of the markers, which was able to be used to assess cognitive functions [13]. Considering them, the importance of cares for elders regarding instructing of physical exercise to avoid progressive loss of muscle mass and to maintain proper gait sped were emphasized [14].

Younger individuals, walking is normally an automatic task, the, the cognitive and conscious component of gait control becomes progressively more important with ageing, possibly to compensate for sensory-motor deficits [15] [16]. Paradoxically, however, decline in the both cognitive and physical function is common in elderly persons. The interrelated decline of cognition and mobility is postulated to be due to underlying shared neural substrates [17] [18] [19]. For example, neuroimaging studies have shown that gait and mobility deficits are frequently encountered in elderly persons with atrophy of temporal lobe [17] and prefrontal area [18]. Additionally, both global cognition and gait speed have been associated with atrophy of corpus callosum [19]. Our findings are only partially supportive of these conclusions. In the linear regression model, usual gait speed was only a borderline predictor of an accelerated cognitive (Table 4).

In the investigation results of characteristics in rehabilitation users, $47 \%$ were with up to junior high school in the educational background, and the higher ratio of current medical history showed the results below; $1^{\text {st }}$ was hypertension (47.2\%), $2^{\text {nd }}$ was cerebrovascular disorder $(22.2 \%)$, and $3^{\text {rd }}$ was osteoarthritis (13.8\%). According to the classification of O' Bryant et al., the percentage of people requiring support was calculated with 26 points or less as MCI [20]. Thus, more than half, 55.6\% were with MCI. According to the Ministry of Health, Labor and Welfare in Japan, the worst cause of needs for long-term care according to the degree of long-term care in 2010 was osteoarthritis (19.4\%), cerebrovascular disorder $(24.1 \%)$ with that requiring long-term care. Dementia was the most common condition, followed by $20.5 \%$ [20].

High blood pressure in certain circumstances and low blood pressure have been associated with cognitive decline and dementia in community-based stu- 
dies, suggested that blood pressure may serve as a viable target for primary or secondary dementia prevention [21]. On the other hand, accumulating evidence suggested that hypertension during midlife may be a risk factor for cognitive decline and dementia [22]. Although relationships of elevated blood pressure during the $7^{\text {th }}, 8^{\text {th }}$ and $9^{\text {th }}$ decades of life with cognitive outcomes have not known yet, several studies indicated that optimal blood pressure ranges for older adults might have depended on earlier blood pressure characteristics [23].

Likewise, cognitive stimulation is essential for elders with hypertension, which tend to have reduced gait speed and worse cognitive performance. As contributions of this research, it was expected that the results could guide geriatric nursing care about detection of changes in cognitive or physical performance of elders, coping with health events such as physical frailty syndrome. Moreover, it has a potential to support discussion on planning of interventions that provide positive results for quality of life in this age group.

\section{Conclusion}

In summary, gait speed could be used for physical fitness in elderly. Gait speed was the best physical fitness measure for elderly. Gait speed of Rehabilitation users was strongly related to MMSE scores. The determinant at Gait speed was MMSE scores.

\section{Acknowledgements}

The authors express sincere thanks to the members of the research and volunteers who participated as subjects.

\section{Conflicts of Interest}

The authors declare no conflicts of interest regarding the publication of this paper.

\section{References}

[1] Friedman, J., Richmond, E. and Baskett, J. (1988) A Prospective Trial of Serial Gait Speed as a Measure of Rehabilitation in the Elderly. Age Aging, 17, 227-235. https://doi.org/10.1093/ageing/17.4.227

[2] Guralink, M., Ferrucci, L., Simonsick, M., Salive, E. and Wallace, B. (1995) Lower-Extremity Function in Persons over the Age of 70 Years as a Predictor of Subsequent Disability. The New England Journal of Medicine, 322, 556-561. https://doi.org/10.1056/NEJM199503023320902

[3] Koyano, W., Shibata, H., Nakazato, K., Haga, H. and Suyama, Y. (1991) Measurement of Competence: Reliability and Validity of the TMIG Index of Competence. Archives of Gerontology and Geriatrics, 13, 103-116. https://doi.org/10.1016/0167-4943(91)90053-S

[4] Haehling, V., Morley, E. and Aanker, D. (2012) From Muscle Wasting to Sarcopenia and Myopenia: Update 2012. Journal of Cachexia, Sarcopenia and Muscle, 3, 213-217. https://doi.org/10.1007/s13539-012-0089-z 
[5] Segev, O., Herman, T., Yogev, G., Mire, A., Giladi, N. and Hausdorff, M. (2011) The Interplay between Gait, Falls and Cognition: Can Cognitive Therapy Reduce Fall Risk? Expert Review of Neurotherapeutics, 11, 1057-1075. https://doi.org/10.1586/ern.11.69

[6] Ostir, C., Berges, I., Kuo, F., Goodwin, S., Ottenbacher, J. and Guralnik, M. (2012) Assessing Gait Speed in Acutely Ill Older Patients Admitted to an Acute Care for Elders Hospital Unit. Archives of Internal Medicine, 172, 353-358.

https://doi.org/10.1001/archinternmed.2011.1615

[7] Ilgin, D., Ozalevli, S., Kilinc, O., Sevinc, C., Cimrin, D. and Ucan, S. (2011) Gait Speed as a Functional Capacity Indicator in Patients with Chronic Obstructive Pulmonary Disease. Annals of Thoracic Medicine, 6, 141-146.

https://doi.org/10.4103/1817-1737.82448

[8] Bramell-Risberg, E., Jarnlo, G. and Elmstahl, S. (2012) Separate Physical Tests of Lower Extremities and Postural Control Are Associated with Cognitive Impairment. Results from the General Population Study Good Aging in Skane. Clinical Interventions in Aging, 7, 195-205. https://doi.org/10.2147/CIA.S31777

[9] Bridenbaugh, A. and Kressig, W. (2015) Motor Cognitive Dual Tasking: Early Detection of Gait Impairment, Fall Risk and Cognitive Decline. Zeitschrift für Gerontologie und Geriatrie, 48, 15-21. https://doi.org/10.1007/s00391-014-0845-0

[10] Martin, L., Blizzard, L., Wood, G., Srikanth, V., Thomson, R., Sanders, M. and Michele, L.C. (2013) Cognitive Function, Gait, and Gait Variability in Older People: A Population-Based Study. The Journals of Gerontology. Series A, Biological Sciences and Medical Sciences, 68, 726-732. https://doi.org/10.1093/gerona/gls224

[11] Mielke, M., Roberts, O., Savica, R., Cha, R., Drubach, I., Christianson, T., Vernon, P., Yonas, G., Mary, M., Robert, I., David, K., Bradley, B., Walter, R. and Ronald, P. (2013) Assessing the Temporal Relationship between Cognition and Gait: Slow Gait Predicts Cognitive Decline in the Mayo Clinic Study of Aging. The Journals of Gerontology. Series A, Biological Sciences and Medical Sciences, 8, 929-937. https://doi.org/10.1093/gerona/gls256

[12] Kinugasa, T., Nagasaki, H., Ito, H., HAshizume, K., Furuna, T. and Maruyama, H. (1994) Effect of Aging on Motor Ability in Men Aged 18 to 83 Years. Japanese Journal of Physical Fitness and Sports Medicine, 43, 343-351. https://doi.org/10.7600/jspfsm1949.43.343

[13] Lenardt, H., Carneiro, K., Betiolli, E., Ribeiro, N. and Wachholz, A. (2013) Prevalence of Pre-Frailty for the Component of Gait Speed in Older Adults. Revista Latino-Americana de Enfermagem, 21, 734-741. https://doi.org/10.1590/S0104-11692013000300012

[14] Cordeiro, J., Del, L., Freitas, S. and Gonçalves, P. (2014) Effects of Physical Activity in Declarative Memory, Functional Capacity and Quality of Life in Elderly. Revista Brasileira de Geriatria e Gerontologia, 17, 541-552. https://doi.org/10.1590/1809-9823.2014.13006

[15] Li, K.Z., Lindenberger, U., Freund, A.M. and Baltes, P.B. (2001) Walking While Memorizing: Age-Related Differences in Compensatory Behavior. Psychological Science, 12, 230-237. https://doi.org/10.1111/1467-9280.00341

[16] Kemper, S., Herman, R.E. and Lian, C.H. (2003) The Costs of Doing Two Things at Once for Young and Older Adults: Talking While Walking, Finger Tapping, and Ignoring Speech or Noise. Psychology and Aging, 18, 181-192. https://doi.org/10.1037/0882-7974.18.2.181

[17] Guo, X., Steen, B., Matousek, M., et al. (2001) A Population-Based Study on Brain 
Atrophy and Motor Performance in Elderly Women. The Journals of Gerontology. Series A, Biological Sciences and Medical Sciences, 56, 633-637. https://doi.org/10.1093/gerona/56.10.M633

[18] Rosano, C., Aizenstein, H.J., Studenski, S. and Newman, A.B. (2007) A Regions-ofInterest Volumetric Analysis of Mobility Limitations in Community-Dwelling Older Adults. The Journals of Gerontology. Series A, Biological Sciences and Medical Sciences, 62, 1048-1055. https://doi.org/10.1093/gerona/62.9.1048

[19] Ryberg, C., Rostrup, E., Stegmann, M.B., Barkhof, F., Scheltens, P., van Straatene, E.C.W., Fazekas, F., Schmid, R., Ferro, J.M., Baezner, H., Erkinjuntti, T., et al. (2007) Clinical Significance of Corpus Callosum Atrophy in a Mixed Elderly Population. Neurobiology of Aging, 28, 955-963.

https://doi.org/10.1016/j.neurobiolaging.2006.04.008

[20] O’Bryant, S.E., Humphreys, J.D. and Smith, G.E. (2008) Detecting Dementia with the Mini-Mental State Examination in Highly Educated Individuals. Archives of Neurology, 65, 963-967. https://doi.org/10.1001/archneur.65.7.963

[21] Ministry of Health, Labour and Welfare (2016) Outline of Prevent Long-Term Care Need and Daily Living Service Projects.

https://www.mhlw.go.jp/file/06-Seisakujouhou-12300000-Roukenkyoku/000008827 6.pdf

[22] Walker, A., Power, C. and Gottesman, F. (2017) Defining the Relationship between Hypertension, Cognitive Decline, and Dementia: A Review. Current Hypertension Reports, 19, 24. https://doi.org/10.1007/s11906-017-0724-3

[23] Rebecca, G. andrea, S., Albert, M., Alvaro, A., Karen, R., Laura, C., Josef, C., David, K., Melinda, P. andreea, R., Richey, S., Lisa, W. and Thomas, M. (2014) Midlife Hypertension and 20-Year Cognitive Change: The Atherosclerosis Risk in Communities Neurocognitive Study. JAMA Neurology, 71, 1218-1227.

https://doi.org/10.1001/jamaneurol.2014.1646 